\title{
China-West Interculture
}

\author{
Kuangming Wu \\ Philosophy Department, University of Wisconsin-Oshkosh, Oshkosh, WI, USA \\ Email: Kmwu2002@yahoo.com
}

Received 3 March 2016; accepted 2 May 2016; published 5 May 2016

Copyright (C) 2016 by author and Scientific Research Publishing Inc.

This work is licensed under the Creative Commons Attribution International License (CC BY).

http://creativecommons.org/licenses/by/4.0/

cc) (i) Open Access

\begin{abstract}
After a brief introduction, "cultures: multi-culture, cross-culture, interculture", this essay proceeds in two major sections, "China and the West in Contrast" on how China and the West inter-differ, and "China and the West in Interculture" on how China and the West interculture. First, three actual examples are cited to show how the West is digital, analytical, in either-or, while China is concrete, subtle, in both-and. Next, logic, time, music, kids, etc., are cited to tell of how China and the West inter-differ to inter-critique to inter-correct, to compose the hope of the world. The vast, exciting, and crucial theme of world interculture, concrete and general, is thus compressed in less than twenty pages. Global interculture is so vast that any essay on it risks playing with vague generality. This essay concretely details two extremely contrasting cultures, the West and China, even on general time, logic, and grammar, starkly how the centralities of eternity and time are reversed, how logic is all bare in the West but turned invisible as bone-structure in China, and how the West strictly enforces explicit grammar while China subtly slides from one word-category to another. Typically, elusive "no do" unintelligible in the West but constantly concrete is story-explained to highlight the West-China contrast. Concrete elucidation of general "global interculture" makes this short essay significant.
\end{abstract}

\section{Keywords}

Culture, West, Interculture, Analytical, Concrete, Global

\section{Introduction}

After a brief introductory section, “cultures: multi-culture, cross-culture, interculture”, this essay proceeds in two major sections; it begins with "China and the West in Contrast" on how China and the West inter-differ, followed by a much longer section, "China and the West in Interculture” on how China and the West reciprocally practice interculture one to the other to thrive the life world.

First, three actual examples are cited to show how the West is digital, analytical, in either-or, while China is 
concrete, subtle, in both-and. Next, logic, time, music, kids, etc., are cited to tell of how China and the West inter-differ to inter-critique to inter-correct, to compose the hope of the world. The vast, exciting, and crucial theme of world interculture, concrete and general, is thus compressed in less than twenty pages.

\section{Cultures: Multi-Culture, Cross-Culture, Interculture}

Our tiny Global Village is crowded with so many cultures; our world is multicultural. And so we tend to hop across cultures from one to the other. But our cross-culture gives us culture-shock, and so we shrink into mesupreme culture-chauvinism, "our culture, right or wrong!” We are right; you are wrong! Conflicts and wars break out. We then have no choice but to inter-culture, to inter-learn to inter-correct to inter-fecundate.

But, saying all this above sounds distant and irrelevant to our daily living. The situation is indeed much more urgent, close to our skin, than we think, as the following common examples show. Is that car moving or staying put? Is the earth flat or round? Is that gaunt taciturn man insane or saintly? They are both moving and not-moving (car), flat and round (earth), and insane and saintly (fellow), both at once unintelligible, until we carefully distinguish how we see and think of these things. It goes this way.

The car is moving if seen from outside, but it is not-moving (the world is zooming past it) when seen from its inside. The earth is clearly vast-flat, seen standing in the midst of wide grassy field, but it is clearly round when astronauts see it from outer-space. That gaunt man is insane to us Americans, but he is the much revered leader in a tribe. "Trance" is mental illness among Americans, but it is much treasured and revered among tribes (Benedict, 1934, 1961). Without how we see and think, things are so jumbled up that we cannot even live.

This "how we see", this perspective on things, is culture. Culture is the stuff of which life is made. We live our culture. But now, we realize that our life world is filled with so many cultures. It is well-nigh impossible to study them all. Fortunately, we see that two cultures are quite in radical contrast if not standing out most conspicuously. They are China and the West.

The West is abstract, analytical, ever in logical either-or. China tends actual, subtle, to both-and. Most cultures can be seen as lying between these two extremes. It would be instructive to study how they differ, to interculture. This is what this essay will do. Since the world today tends to take the West as dominant if not solely "proper", we will purposely tilt to China; the West will be described almost unfairly.

\subsection{China and the West in Contrast}

Three examples are given here, to highlight the contrast between China and the West, $1+1$ as 2 or not, "square" and "round" as exclusive or not, and "no do" outside "do" exclusive of "not do". In them, the West is consistently digital and precise, analytical and systematic, and comprehensive and restrictive. China is opposed to them all in the West. All this is quite a sight to behold. We now go into them one by one.

Our first example is that well-known " $1+1=2$ " a favorite of Western thinking, saying that $1+1$ simply, absolutely, and logically must be 2 alone, not 1.9, not 2.1. Here the West is digital and precise, eternally abstract. But then here comes China, insisting "not quite so". " $1+1$ " deposited in a slot machine can come out a zero. One spouse plus another spouse can produce more than 2 children. And of course one load of explosives plus one spark can produce thousands of splinter-pieces. So, " $1+1$ " can be " 0 ”, several, and a thousand, all depends on how an actual situation goes.

Interestingly, the last example of explosives with a spark is proposed by a master logician Whitehead (1910-1913). He was so extra-logically sensitive enough to explode logic with this example of exploding explosives, to conclude, "The [logical] exactness is a fake". In his "Immortality", Whitehead (1961) did not go beyond this negative blast on Western logic. We go beyond the West to interculture with concrete China. This blast was his last public statement; it was quite a significant death knell to logical thinking that is analytical and precise, in the West.

Our second example is if square and round is exclusive vs. not. Western geometry would of course insist that square is square, round is round, and the twain shall never mix or meet for all eternity. The West is here quite analytical and eternally separative. Meanwhile, China would cite just one concrete counterexample. Look at the plump healthy baby our treasure; her face is actually a round square so irresistible!

Her face as a perfect round square is what is priceless that grabs our heart and soul. Her future is also a round square, as her round square face tells that her tomorrow is displayed today; she is the "tomorrow today", as impossible to mix as a round square! Her face cannot be brushed aside because she is starkly present right here 
now, smiling in her Mom's embrace. No logical reasoning can oppose an actual case, now can it?

Our third and final example is "no do", that elusive "wu wei", outside usual "do, wei" exclusive of "not do, pu wei". We just said "elusive”, but "no do" is elusive for the West alone whose thinking has only "do" and "not do" as the all-comprehensive repertoire of action, quite restrictive. For all its elusiveness in Western logic, however, "no do" is quite common and concrete, as China smiles and says, "Here is its ordinary example quite usual".

Tommy was shouting and playing, all in so much fun, when Mom suddenly called, "It's time for your nap, Tommy”. Wow, he turned so angry, shouting at Mom, "No! No! No nap!” For him, "nap” is a dirty word; the world was so exciting that it can ill afford missing by napping for Tommy! But his angry shouting clearly shows how badly he needs a nap! Have need of nap but don't want it-Mom has a dilemma on her hand, for Tommy.

Now, Mom cannot simply let him go; in his fatigue he would stumble and get hurt. She cannot practice "no do" on him. Still, Mom cannot grab him and push him into bed, with a shout, "Sleep!" Such tactic of "do" would start WWIII! We know Tommy is the flesh of her flesh to Mom; Mom must perform some practice outside "do" and "not do". But "do" and "not do" exhaust all alternatives to Western thinking. Look at the miserably unintelligible explanation of "wu wei" as "non-purposive action" by logical Munro (who taught logic-obsessed Chad Hansen). How could an act be "non-purposive?” Is such acting a purposeless wandering (Munro, 1969)?

Mom in her bodily intimate love then naturally says, trailing Tommy, "OK, Tommy. No nap for you. Just come sit here on your bed, but don't nap, OK? I'm going to tell you your favorite story. OK?” Tommy agrees to this delicious deal and comes and sits on his bed. Mom slowly begins, "O-n-c-e u-p-o-n a t-i-m-e, a long, long time ago, there lived an old lady named "Tiger Dame”". Tommy hits his pillow. Mom tucks him in, in such "no do" of love so tender so natural!

Now, looking back, we see that all three examples have one feature in common. They are championed by Western thinking that is abstract, precise, in either-or, and such logic is consistently opposed by softly concrete citations of actual situations irresistibly ordinary and common. We can clearly discern the stark difference between Western culture and Chinese culture, one is abstract either-or, another, disarmingly concrete. Three more examples, all general, time, logic, and grammar, will be concretely explained to highlight the stark China-West contrast as abstract vs. concrete, logic vs. storytelling.

On the whole, then, we must agree with the master logician Whitehead on the plight of Western logic, that the exactness of logic there is a fake. This is a sad tragedy. Still, sadly, the above threefold story-argument, in concrete way from actuality, amounts to justifying Whitehead's judgment. But of course it is so easy to poke holes in a fake system. Nothing has been done on building up a positive tapestry of reasoning in actuality. China has a job cut out for it. How can China do it? To think of it, the above way of arguing is itself already an enactment of concrete thinking, story-argued, that trails the pearl-way through concrete actual things; the pearl-way is of course the Li 理 (Ding, 1959), the Tao. Such trailing reasoning in actuality on actuality must itself happen actually, never contrived. Spontaneity of this reasoning shows its authenticity. What must be done here is to develop actuality-reasoning systematically. "System" here is the system of Mother Nature. Of course "system" has many senses. See "Four Senses of 'Being Systematic”' (Wu, 2010, 2012).

It has been my contention for decades that China has a distinctive fourfold mode of thinking, all uniquely its own; Chinese thinking is an alternative to abstract analytical logic of the West. China's reasoning is in four prongs, concrete thinking and story thinking based on body thinking in music reasoning (Wu, 1997, 1998, 2010, 2011). In fact, we have just enacted such concrete thinking.

All the above reasoning by examples enacts story thinking. Specifically, Mom's wu wei on her beloved Tommy came from her body thinking on Tommy her bone of bones, her flesh of flesh. And all such reasoning is concrete thinking, all chanting delightful music with Tommy the kid. But an overall completed tapestry is still far off in the future, to dawn China’s actuality-reasoning. Bruckner's rare String Quintet, quite long, undergoes chanting "harmony in dissonance"; it is an ideal community of interculture antiphonal, coming over us so rare now yet. Music sings future.

Sadly, Bruckner's singing vision of the united nations of united cultures is still far, far off. Bloodshed is rampant everywhere mostly due to racial prejudices, such as anti-Semitism, anti-blacks, anti-Koreans (sin Japan), and the like. Birds of a feather naturally flock together, usually, but consanguineous marriage among siblings is an assured deterioration in blood and in culture. Birds of a feather are absolutely of no help at all. Birds of different bloods invigorate.

The key issue here is "difference": "You differ, so you are rejected" is a natural but terrible mistake on all counts. Difference is the crucial key to inter-fecundation toward progress in every sense. Cultivation of reverence 
for difference, cherishing differences, is indispensable to world interculture. Interculture essentially implicates inter-mixing and inter-learning to inter-enriching all of us. No-difference implies no inter-renovation; it is death of all things.

We have indicated so far above the differences between the West and China. The theme deserves detailing a bit. These differences are shown in the writings that record differences in the way each culture thinks. In China, “small 小 ([minutely] | divided 八)", is a little different from “few 少”. “Name 名” is my mouth 口 shouting “Hey, it’s me! Don’t shoot!” at dusk 夕. “Marriage 婚” occurs when taking a woman 女 in the evening dark 昏 (Ding, 1959).

Such is how ideographical thinking tells actual stories to portray daily ongoing, while alphabetical thinking arbitrarily designates phenomenal happenstance by arbitrary combination of arbitrary signs quite meaningless in themselves, and results in abstract analysis quite indifferent to concrete actuality. Such alphabetical thinking shapes exact logic in neat legislation, while ideographical thinking naturally mirrors to follow actual ongoing, however it happens concretely.

This is why, in alphabetical thinking of the West, grammar the rule of word arrangements is explicitly formulated and strictly enforced, on pain of loss of meaning, while ideographical thinking in China facilely slides among parts of speech and in and out of grammar, to tend toward verb-vividness. Actuality shapes word order that has no independence. Can you imagine Han Yü 韓愈 saying, “Those entering China-ethos, we 'China' them" (Confucius \& Dawson, 2008)? Such saying-freedom is what makes people say that China has no grammar. China punches instead!

On the whole, alphabetical thinking is needed for its exactness by ideographical thinking portraying things actual, as precise analysis of alphabetical thinking is empty without the concrete content of ideographical thinking. Each mode of thinking differs from the other to complement the other. China-West interculture indispensably lets thrive these two contrasting modes of thinking. But now, what is this "interculture?"

\subsection{China and the West in Interculture}

In the meantime, I hear you shouting at me, "Hey, what has it been going on here? You claim to elucidate the Chinese way of thinking, while you yourself have been quite analytical, digital, and systematic, exactly as the West, in all your presentation of China. Is your China-shop hanging a China-head and selling the Western meat, with shops hanging sheep-head to sell dog-meat?” Wow! Thank you so much, my friend, for such sensitive observation!

Well, I do not know about being "analytical" exactly as the West, but I do go step by step (as you call it "digital") to specify my points to "systematically" present China in its distinctness. Such is what any decent "thinking" does, whether Western or Chinese. The West shows its thinking in all its glories. I do wish to learn more and more from the West on how to think clearly and precisely.

In its clear presentation, I do hope China appears as distinctly Chinese. Being distinctively Chinese, however, China is never abstract but is ever concrete. China never theoretically argues but ever concretely reasons. China has no rational universality; instead, China aspires to actual story-ubiquity. Concrete generality is attained by pars pro toto, starting at a concrete specific, to metaphorically spread to other concrete specifics, "as this, so that, likewise". China has no "seeing from nowhere". The incredible Thomas Nagel (1989)'s The View from Nowhere is possible, if at all, only in the West, abstract and theoretical.

All the above examples elucidated are incurably actual and specific, proposed for the readers to apply to other concrete cases appropriately. Such metaphorical expansion from one specific instance to many other similar cases, all actual, is typical of China's concrete reasoning. Such is how China intimately trails the pearl-way of all things concrete. All this is concrete thinking peculiar to China.

Moreover, such concrete thinking needs to become precise, not irresponsibly vague, and coherent from one item to another, not scattered unintelligibly all over. To shape up such concrete thinking, China must look to the West rightly proud of being logically tight, analytically clear, and systematically comprehensive. Of course the West has been sadly judged "a fake" by its master logician Whitehead. Still, fake clarity and precision can still serve a standard to shape China out of its tendency to be vague, imprecise, and scattered incoherent.

Still, China remains proudly Chinese. Its trailing concrete thinking is bodily undergone (in body thinking) by telling stories and thinking story-way (as story thinking). And all this is fun, congenial to Tommy listening to stories heartfelt and repeatedly, as he jumps up and down so playful, humming songs he has made for himself. Tommy practices body thinking. China's concrete thinking in body thinking and story thinking is music thinking. 
And remember this. No one is softer and weaker than children, and no one is more resilient and stronger. They get hurt so easily, sometimes quite seriously, and they bounce back as the completely new balls-balls are their favorite-in no time. Don't we want to be such kids, tender and tough? After all, kids begin life, and the beginning is always filled with kid-vigor, an unlimited reserve of wobbly energy for tomorrow.

Kids are tomorrow today, and no future power can be looked down upon. That is why they are forever humming, for no reason whatever, for living fun for the uncertain future-full of unimaginable possibilities—is fun enough to sing along, isn't it? Tender and tough, wobbly and full of vigor for tomorrow not even they would know, kids are the closest on earth to divine angels. Mom and Granny are all sold on these kids so dirty so messy, and so naughty, ever humming.

Such concrete thinking body-lived and story-thought is forever jumping alive-what concrete body is not alive as kid? We are now all alive as kids and with kids irrepressibly romping around singing all over. We are all kids of all ages, Bruckner one among them. After all, what is life without singing fun? No fun, no life, counsel our august children shouting at us to come over. We simply must join them; otherwise we die of no songs and no fun.

Music has been mentioned so often above; it is uncanny in all its power all powerless. As the exclusive art of time, music constantly moves on. But music is also where our tired soul dwells at rest motionless, resting comfortably at home. Music is an art of sound, and sound is intangible, nowhere. Sound resounds hollow, everywhere nowhere. But the sound of music delivers impacts incredibly total, thorough, and devastating, positively and negatively.

All things and all atoms, all joys and sorrows, and even silly dogs barking, are all composed of rhythm rhyming and dissonant, and rhythm is music, and so all things are composed by music and composed of music. Music moves the hearers to move the world. The music of my heartbeat resounds with the music of the spheres everywhere, heavenly and earthly, even sung by silly barking dogs. Count their barking rhythm, and we will hear the music of the spheres. In the beginning is music, to round up all things at the end, for all is well that ends well, and music ends all things well. The end of all things, new Heaven and new Earth, resound with trumpets and with whispers day and night bright as day, and day is at rest at home as night—all thanks to music. Music sets the world in joys over sorrows by creating the world. In solos or in antiphony, music is always "I and Thou" (Buber, 2000). Music is sadly missed in Martin Buber (2000)'s philosophical poetry. The volume is musical, despite lack of "music" as a specific theme. Music is where no single thing is alone, as in music all things are together.

Togetherness con-cresces (Merriam-Webster's Collegiate Dictionary, 2008) to concrete, and so, as intangible, music is concrete, all too concrete. All poetry, all sculpture, all paintings, and all architecture are all music flowing, as the essence of beauty is music jumping alive rhythmic. Kids of all ages gather at the slightest humming of music. Even the autistic people are awakened to respond in all smiles to music, to join our community of music so basic to humanity and to the world.

“All this is fine, but how did you get into children and music while you are talking about China?” Oops, I've got carried away. I apologize. But, to think of it, connecting children are China is inevitable, seeing that body thinking in concrete thinking and story thinking are alive, and no one is fittingly alive as children singing constantly. In fact, this body thinking concrete way in China is how children routinely think and sing their thinking. This connection leads us back to China. The situation is still rife with contentions, as any concrete situation rarely has halcyon calm for too long.

Eyebrows have been raised that I simply practiced Western logic when I advertized to elucidate Chinese way of thinking. With gratitude, I now respond in four ways, logic as essential to thinking, logic as bones of my body thinking, logic as tacit, and logic as to play with.

One, logic as essential to thinking: Let us begin at the rock-bottom beginning of all things whatever. Being logical shows being reasonable, and being logically reasonable spells constitutive coherence of the sanity of the body of any existence. Here is a concrete example. My uncle was a rare genius in Taiwan under Japanese occupation. He earned a Ph. D. in law, and another Ph. D. in economics, both from the Imperial University in Tokyo, the top university as Oxford and Cambridge combined in Japan.

He told me that he can deal with anyone he meets except for an insane dog and a "ken pei”, FBI and Gestapo combined in Japan. This is because he does not know what they are thinking at the moment, and they can change mind at any moment. They are all "cracked up", with broken pieces scattered all around. No one can handle the existential incoherence of being illogical. Logical incoherence shows a breakup of the whole body of 
existence itself. Logic shows existential coherence.

Two, logic as bones of my body thinking: Thinking is activated throughout the whole body of my existence. Not only does my brain think. Even my finger-tips write out my thoughts; my ideas are nowhere until they appear written out by my fingers on paper. Thinking is radically body thinking. But do my bones think; what about my bones invisible? I move to show my bones moving; my bones I cannot see are the logic that is I myself thinking. This point is interesting, deserving to detail.

Without my bones moving, I cannot move, but usually I pay little attention to my bones; I just move on in daily ongoing. Without my bone-logic operating logically, I cannot think, but paying attention to such bonelogic borders on abnormal pathology. I just go on "arguing”, as I quarrel, debate, and reason. Logic is essential to any thinking, but logic is hidden tacit in my actual thinking. Logic is my bone thinking.

Three, logic as tacit: Still, logic constantly operates in thinking; no logic, no thinking. How does logic operate in my bodily thinking? My hero Chuang Tzu in ancient China vigorously debated with the world-renowned logician Hui Tzu, almost on a daily basis. When Hui Tzu died, Chuang Tzu sorely missed him at his grave. He lamented over the loss of his logical plate to pound on with (24/48-51). All this while as they logically debated vigorously, not once was the word "logic" mentioned. Logic was conspicuously present, and no "logic" appeared among the logician and his debater. Such was how "logic" was handled in logical debates; "tacit" is logic in logical debates.

Four, logic as to play with: All this shows how "logic" is played, in China. Such is far from the case in the West, however. The West is all-obsessed with logic that is based on " $\mathrm{A}$ is $\mathrm{A}$ " and operated on such principle of identity. And then the West pounds on its derivative, "A is not not-A"; self-identity sires an opposition to contradiction. Things contradictory are false and even impossible to exist. And that is that, so the West insists; all things whatever are either logical consistent or else illogical contradictory, a no-no and cannot even exist!

In contrast, China takes logic as something to play with; China plays even with falsehood, contradictions, non-sequiturs, and the like, as ploys to metaphors, evocations, and ironies. This is because actuality is filled with such logical atrocities. Actuality is both logical and illogical, being logical while illogical, being illogical yet implicating something logical in things. So should our actuality-thinking be, playing lightly with logic as we think trailing the pearl-ways of concrete things. So insists China.

If all this sounds too esoteric and abstract, look at the dirty kids all so messy ever shouting at one another, all lustily at play. Kids play with their whole body-coherence. And they thoroughly make sense; they are perfectly "logical", though they seem so "silly" to our po-faced adult-logic. Still, those kids could not care less about "logic" they do not even understand. They just give all their bodily living to playing, and their play is totally body-coherent, sensible and logical, and they never care for "logic" devil may care! Kids live singing logic; their logic is music_at play. Kids are the lived ultimate of "logic supreme!"

It is thus that logic is stressed as an either-or in the West; logic is played with in China as an elusive both-and. As a result, the West is precisely logical, while China is subtly literary and historical. China is proud of being a culture of "literary history 文史”. It is abundantly clear, then, as to how China and the West should do their best to learn from each other, to each fecundate by the other. So, we have cited just one instance, "logic" that is concrete beyond concrete. And we have just shown that "logic" can exhibit interculture between China and the West, dynamic and interactive. Let me be more detailed and precise.

Nothing is more precious than my self-all begins here. The world begins at my right hand vs. my left hand. Kant is observant enough to say so (Spicker, 1970). Myself is all my body-alive, not just physical body but physis in the original sense of organic and holistic genesis, growth, and structural organization (Peters, 1967). Insights on my body originating the world and my body as physis came from the West, but the West sadly discards their own insights, to be picked up and developed by China.

China is full-bodied, "me, myself, and I", as my full-bodied boy Peter taught me. As the full-bodied self, China thinks body thinking. All thinking is autobiographical—all thinking tells about how and what I am-to engage in story thinking, to compose concrete thinking. All this describes how China thinks. Its thinking is in story-mode that establishes, elucidates, and expands the world. Even story thinking operates in three ways. Stories can be told as, a, illustrations of an argument already set; story can, b, sway an argument or reinforce an argument unexpectedly; or, c, story can guide an argument to mirror how things go actually.

In a, the story follows argument. In b, either can follow either. In c, argument follows story. At most the first two ways are followed in thinking of the West, as shown spontaneously by Rorty (Huang, 2009). Only China practices story-thinking in c-mode, as what story thinking proper should be. Such story-thinking is a "big deal"; stories create the world, as our wise American Indians counsel us (Frey, 1995). 
Let us now go a step further. China thinks actuality-thinking body-thought, where bone-logic is hid invisible. Logic hid, China tends subtle and even imprecise, in need to learn from the West. The West is analytically precise, having abstracted itself from cluttered actuality to turn analytical, universal, and exclusive of differences to turn neatly exact even into a "fake" reality. The West needs be grounded and earthed; it needs China to embody thinking to be actualized. This essay on China-West interculture is informed by the West analytical to a fault, to "a fake”. But, fake or no fake, Western precision serves as a convenient plumb-line to help steer thinking in China toward exactness of concrete operation.

Do we need an example to concretize the above theme? Here is one. In the West, time is a mere shadow, non-existent, of eternity on the screen of logic eternally set; Plato's Republic 514a-521b indicates as much (Cornford, 1941). In China, on the contrary, time is king; “That was one time, this is one time”, says Mencius 2B13. Even the "images that move" are the logic of time.

In China, eternity hovers over time and haunts time, to settle time as time ever-here is eternity! —-moving. Such moving time is punctured occasionally by “occasions”, when time stops to peek at itself, still moving. The logic of time moves in falsities, contradictions, and non-sequiturs as they are unstable-that is why they are spurned by the West's eternal logic_-and are embraced by China-in-time to move on into history. History now turns literary, and both show how logic is timely, all too timely.

In this embracing both-and way, accepting both truths and no-truths, Chinese logic prances-logic in China does prance!- - even in "A as no-A" to evoke, that is, to call-out the next, all unexpected, as "expectation" does not move, and as the "next” shows time nodding forward. All this is logic moving as time. Such is China. ChinaWest interculture shows itself in "time". Time actualizes interculture.

Now, if time all-ubiquitous can make specific China and specific West inter-culture, then anything specific or general, concrete or analytical, can induce world interculture. Who said the world is hopeless? The world hope consists in cultures interacting inter-learning to inter-correct to inter-fecundate, and as long as such interculture keeps going, the world is constantly renewing itself to rid of any stagnant corners that can breed mistakes and mishaps. Things that move cleanse themselves; time and history that move on this way give hope to the world.

Not accidently, natural science has an absolute faith in "tomorrow", any tomorrow whatever! The future is forever rosy to scientists! Now, we can reflect on this fact. Rather than condemning such blind "faith” wholesale as gun-ho "scientism", perhaps we should discern a grain of truth in this science-idolatry on account of future-idolatry, and join science and scientism in trusting ourselves to timely dynamics of world interculture where our true hope resides, both ubiquitous and specific, both analytical and concrete actual. It is important to save oneself from wholesale condemnation in all haste by giving science a phoenix-resurgence from its ashes.

Now, let us be cautious here. How does our faith in timely dynamics of world interculture differ from scientific trust in the future whatever? Scientists just in haste generalize from the "continuous progress" they see made in the past to infer their trust in tomorrows whatever, but the past guarantees no future. In contrast, we trust in time-dynamics of interculture by reason of interculture as inter-learning in inter-cleaning inter-correcting. Continuous corrections by mutual cultural critiques quite sober yield the sober hope in world interculture on time scale (Wu, 1965). World interculture exemplified by China and the West interacting composes world hope.

Our life world is filled with so many cultures, but they need not be looked around for to see. Any neighborhood, mine, too, jostles with them so many. "Many" implicates "different" where we notice at once mistakes, tons of them. All things begin here, noticing different mistakes. Jesus says I must first remove my eye-plank before cleaning your eye-speck, but I see no plank in me; all I see is your specks so many (Henry, 2003). So I just go ahead and clean up your specks and allow you to clean mine as well, and all specks and planks vanish.

Such is inter-reverence that is surprisingly easy, easy as seeing your specks and cleansing them; and it is all reasonable and so natural. All this is interculture that is the assured fool-proof hope for the world, as sure and easy as seeing all our warts and snags, all our dents ad mistakes, and removing them one by one. Our common saying, “advice is a dime a dozen”, tells of how widespread if not "easy” (to us) finding fault and correcting mistakes of others are. We all begin here. Anyone can do it; we all must do it. We begin right here at ChinaWest interculture that is almighty all-easy, and all-needed. We hum along together our gut-music of tuneful turns that is our intimate China-West interculture.

\section{References}

Benedict, R. (1934, 1961). Patterns of Culture. Boston, MA: Houghton Mifflin. 
Confucius, \& Dawson, R. (2008). The Analects. New York: Oxford World’s Classics. Oxford University Press.

Cornford, F. M. (1941). The Republic of Plato, tr., Francis Macdonald Cornford. Oxford, England: Oxford University Press.

Ding, F. (1959). Shuowen jiezigulin 說文解字詁林. Taipei: Shangwuyinshuguan.

Frey, R. (Ed) (1995). Stories That Make the World: Oral Literature of the Indian Peoples of the Inland Northwest. Norman, OK: University of Oklahoma Press.

Henry, M. (2003). Matthew Henry's Concise Commentary on the Whole Bible. Nashville, TN: Thomas Nelson.

Huang, Y. (Ed.) (2009). Rorty, Pragmatism, and Confucianism. Albany, NY: State University of New York Press.

Merriam-Webster's Collegiate Dictionary (2008). Merriam-Webster's Collegiate Dictionary (11th ed.). Springfield, MO: Author.

Munro, D. J. (1969). The Concept of Man in Early China. Palo Alto, CA: Stanford University Press.

Nagel, T. (1989). The View from Nowhere. New York: Oxford University Press.

Peters, F. E. (1967). Greek Philosophical Terms: A Historical Lexicon. New York: New York University Press.

Spicker, S. F. (Ed.) (1970). The Philosophy of the Body. Chicago, IL: Quadrangle Books.

Whitehead, A. N. (1910-1913). Principia Mathematica. London: Cambridge University Press.

Wu, K.-M. (1965). Existential Relativism. Unpublished PhD Thesis, New Haven, CT: Yale University.

Wu, K.-M. (1997). On Chinese Body Thinking: A Cultural Hermeneutic. Leiden: Brill.

Wu, K.-M. (1998). On the "Logic" of Togetherness: A Cultural Hermeneutic. Leiden: Brill.

Wu, K.-M. (2010). Chinese Wisdom Alive: Vignettes of Life-Thinking. New York: Nova Science Publishers.

Wu, K.-M. (2011). Story-Thinking: Cultural Meditations. New York: Nova Science Publishers.

Wu, K.-M. (2012). Nonsense: Cultural Mediations on the Beyond. New York: Nova Science Publishers. 